\title{
LA RED NACIONAL Y LA INTEGRACIÓN DE LOS MERCADOS ELÉCTRICOS ESPAÑOLES DURANTE LOS AÑOS DE ENTREGUERRAS. ¿OTRA OPORTUNIDAD PERDIDA?*
}

ISABEL BARTOLOMÉ

Instituto Superior de Ciências do Trabalho e da Empresa ${ }^{\mathrm{a}}$

\begin{abstract}
RESUMEN
Este artículo examina la oportunidad del tendido de una red nacional de interconexión eléctrica con anterioridad a la Guerra Civil. Estas mallas se comenzaron a tender en Francia, Suiza o Gran Bretaña durante el decenio de 1920, despertando en España un vivo interés entre los técnicos y en la propia Administración, que promovió sucesivos concursos para la información del proyecto. Sin embargo, ninguno de los planes prosperó y hubo que esperar casi medio siglo para ver concluido el cableado de la península. Aquí se describe el estado de la transmisión eléctrica en España hasta 1936 y se analizan las causas de la contención pública. Se arguye que la red no hubiera resuelto por sí sola los bajos rendimientos del sector eléctrico prebélico, en tanto ésta no representaba una alternativa a la construcción de grandes centrales dotadas de embalse, sino sólo una parte de las inversiones precisas para un eventual proyecto de electrificación a gran escala.
\end{abstract}

Palabras clave: industria eléctrica, transmisión eléctrica, regulación de mercados eléctricos.

\footnotetext{
* Este artículo es una parte del capítulo 4 de mi tesis doctoral, defendida en Florencia en junio de 2003 y que supervisó el profesor Jaime Reis. Agradezco encarecidamente a los evaluadores de la Revista de Historia Económica, y a mi amigo Emilio Pérez Romero, su atención y sus perspicaces comentarios.

a Departamento de História, Avenida das Forças Armadas, 1649-026 Lisboa, Portugal. isabel_bartolome@yahoo.es
} 


\begin{abstract}
This essay examines the opportunity of erecting a national electricity network before 1936. Regional markets were created by coordinating electricity networks in France, Switzerland and Great Britain during the twenties. In Spain, a review of technical journals indicates that this issue had become significant in the nationalistic economic policy environment of the inter-war period. The Spanish Government made several attempts at setting up a national electricity grid through public tenders. However, none of the projects succeeded and the development of an electricity-grid was left to private firms' initiative and the network did not achieve a national coverage until the 1980s. Seen from the standpoint of the 1930s, the high investment costs the interconnection required rendered this project unfeasible. As a matter of fact, a national-grid may not have represented an alternative to dam-building in order to improve the efficiency of the Spanish electrical system.
\end{abstract}

Keywords: electrical industry, electricity-grid, electricity market regulation JEL Classification: N74, H54

\title{
1. INTRODUCCIÓN
}

...«Las redes eléctricas harán muy pronto en la vida industrial de un país, el papel, no sólo del sistema nervioso que transmita el pensamiento y la dirección, sino de un sistema circulatorio, que distribuya el calor y los elementos de vida, y aun de sistema muscular que transmita a todos los órganos la fuerza, el movimiento y la energía» ${ }^{1}$.

Tras 50 años de existencia, el sector eléctrico español había alcanzado en vísperas de la Guerra Civil un desarrollo notable. Éste era el resultado de la explota de los recursos hídricos del país mediante el uso de tecnología muy avanzada en el ciclo de generación. Esta gran industria a escala nacional era, no obstante, relativamente pequeña cuando se comparaba con sus análogas italiana o francesa. Un discreto sector suministrador que se correspondía con el escaso cambio estructural que el empleo de la energía hidroeléctrica había inducido en territorio español. Las condiciones naturales para la generación de energía eléctrica en España explican en buena medida el crecimiento limitado de su industria: sus saltos no eran los más adecuados para aplicaciones intensivas del fluido y los usos discontinuos, fabriles y domésticos, marcaron la pauta de crecimiento del sector suministrador. Esta orientación de la demanda española de electricidad anterior a la Segunda Guerra Mundial constituía una excepción en el panorama de los paí-

\footnotetext{
${ }^{1}$ Pérez del Pulgar (1915, p. 411).
} 
ses hidrodependientes de Europa. En la mayoría de ellos, la hidroelectricidad había impulsado aumentos marcados de la intensidad energética en sus economías, que a su vez repercutían en unos rendimientos de la maquinaria de generación que duplicaban o triplicaban los correspondientes al parque eléctrico español².

La literatura económica señala que el mal que aquejaba al sector eléctrico español, la baja utilización de los sistemas de suministro, se enjuga con una mejor integración de sus unidades productivas y de sus núcleos consumidores. En las industrias eléctricas, que se caracterizan por un incremento constante de la escala derivado de su orientación reticular, las redes eléctricas contribuyen a garantizar el servicio mediante el contrapeso de diversos recursos productivos y la compensación entre diferentes grupos de demandantes. Se amortiguan así las incertidumbres que provocan tanto la imposibilidad de almacenar energía eléctrica, si no es a escala ínfima, como el desconocimiento efectivo de cuál va a ser la demanda instantánea. La interconexión permite conjugar los períodos de punta de diferentes centros de consumo, que pueden no ser coincidentes, y, así, garantizar la cobertura del sistema eléctrico sin recurrir al aumento del parque de generación.

Aparte de la continuidad del servicio y el reparto equitativo de las cargas entre las diferentes centrales, los sistemas de interconexión procuran la igualdad en la tensión y frecuencia de los envíos. Esto significa que, en las grandes escalas productivas de esta industria, los rendimientos mayores no derivan tanto de los grandes generadores como de una mejor coordinación en cada uno y entre sus diferentes ciclos -generación, transporte y distribución ${ }^{3}$.

En las modernas organizaciones eléctricas, se distingue entre sistemas de transmisión y sistemas de interconexión. Los primeros comprenden el transporte de fluido eléctrico desde el punto de producción hasta la zona de consumo y las diferentes transformaciones de tensión que esto conlleva: la elevación de la tensión en el punto de la generación y la disminución de aquélla en el área de distribución. Los escollos técnicos básicos de la transmisión fueron resueltos en 1891, cuando se comprobó en Frankfurt la viabilidad del sistema universal para sucesivas transformaciones en corriente alterna. Las primeras transmisiones a larga distancia fueron ésta, con una longitud de $175 \mathrm{~km}$ y a una tensión de $25 \mathrm{kV}$ y la emblemática de Niágara-Búffalo de 18964 . A su vez, los sistemas de interconexión, cuyo propósito era integrar cargas, crecieron hasta alcanzar la escala regional y luego nacional durante el período de entreguerras. Se sobrepasaron entonces los 220 kV en la tensión de estas transmisiones, al mejorar los conductores y el aisla-

\footnotetext{
${ }^{2}$ Errandonea ofrece datos para 1933 según los cuales la media italiana era de 2.599 horas de uso del conjunto de la potencia termo-hidráulica y en España de 1.642. Errandonea (1935b, p. 532). El caso español en perspectiva europea en Bartolomé (2003, capítulos 1 y 2).

${ }^{3}$ Eden (1981, pp. 154 y ss).

${ }^{4}$ Williams (1986, p. 109 y ss). Hughes (1983, pp. 129 y ss).
} 
miento de los cables. La regulación automática de las cargas se resolvió casi simultáneamente ${ }^{5}$. A partir de entonces, pudo pensarse en la construcción de grandes redes nacionales de intercambio, sustituyendo las transmisiones punto de producción-punto de consumo por mallas de interconexión 6 .

Desde 1945 hasta ahora, el control central y público de estas redes, como corazón de un sistema eléctrico, ha sido rara vez objeto de controversia. Por una parte está la cuestión estratégica, pues las líneas transportan energía, cuyo suministro se considera básico. Pero, por otra, la integración física de un sistema eléctrico representa el ciclo productivo más sensible a la aparición de rendimientos crecientes de escala y este monopolio clásico ha reclamado la intervención de instituciones públicas para su regulación ${ }^{7}$. Desde entonces, y en la mayor parte de Europa, tanto la homologación del soporte físico como la extensión de las líneas de transmisión e interconexión ha corrido a cargo de la autoridad pública, cuestionándose ésta muy poco durante el proceso de desregulación de los mercados eléctricos europeos vivido desde $1980^{8}$.

Entre ambas guerra mundiales, cuando tender redes nacionales comenzó a ser factible técnicamente, se animó un vivo debate en torno a su utilidad y al grado de control público de la infraestructura. Los pioneros, como Siegel en Prusia y Pérez del Pulgar en España, comenzaron a intuir en 1915 los efectos dinamizadores que una intervención del Estado pudiera tener en este sentido. Incluso en Francia y en 1917 se creó una comisión, presidida por Monmerque, para averiguar las potencialidades de la construcción de una red nacional ${ }^{9}$. No obstante, las primeras iniciativas se retrasaron hasta 1925, con el tendido paulatino de embrionarias redes de interconexión en Suecia, Alemania, Suiza, Inglaterra y Francia ${ }^{10}$. Y, pese a estos ejemplos, Italia y Noruega, que albergaban sectores eléctricos muy desarrollados, no las emularon; España, tampoco. Hacia 1936, y a iniciativa de las propias compañías de suministro, apenas se habían tendido algunos cables de conexión interregional en estos países. La prolífica historiografía italiana ha seguido

${ }^{5}$ Aunque Ramunni (1987) señala que, a lo largo de los años veinte, la puesta en uso en Francia de sistemas eléctricos integrados puso de manifiesto nuevos problemas de orden práctico.

${ }^{6}$ En el decenio de 1920 se sucedieron al menos cinco «Conferencias Internacionales de las Grandes Redes Internacionales a Alta Tensión» en las que se intercambiaban hallazgos y experiencias y de las que queda constancia en la prensa técnica. La mejor síntesis sobre el conocimiento de la época en torno a las redes en Mortara (1934, pp. 447 y ss). Segreto (1993, pp. 362 y ss) realizó una comparación sobre la situación de las distintas redes de intercambio de energía en Europa. Recientemente, R. Milward (2004) ha descrito, a partir de literatura secundaria, el proceso de constitución de algunas redes nacionales en la Europa de entreguerras.

${ }^{7}$ Joskow y Schmalensee (1983, p. 65). Esto no impide, sin embargo, que los ciclos de generación y distribución constituyan segmentos competitivos y, de hecho, el transporte ha de proporcionar las condiciones para no impedir que aquéllos lo sean. Joskow (1996, p. 358).

${ }^{8}$ Un panorama de la desregulación de los mercados en Gilbert y Kahn (1996).

${ }^{9}$ Véase, Sintés y Vidal (1933, pp. 145 y ss).

${ }^{10}$ Algunos detalles sobre Alemania, Inglaterra, Suecia o Francia en Milward (2004). 
la opinión de los coetáneos que se quejaban de que la actitud conservadora de sus compañías eléctricas obstruyó la integración de sus mercados eléctricos durante los primeros treinta. Se considera que allí las empresas bloquearon las iniciativas de la Administración a favor del tendido de la dorsal Norte/Sur a cambio de la salvaguarda de mercados compartimentados regionalmente ${ }^{11}$.

En el caso español, la literatura económica también ha imputado a las sociedades eléctricas la responsabilidad de su malogro por parecidas razones ${ }^{12}$. Sin embargo, esta actitud renuente hacia la integración extrañó a los propios contemporáneos, que advirtieron cómo la discontinuidad de los mercados eléctricos en 1935 no hacía más que agravar el déficit de sus recursos naturales: las dificultades en la generación hidroeléctrica de centrales aisladas se solventaban con centrales térmicas de reserva cuya potencia permanecía casi siempre desocupada, resintiéndose los rendimientos del conjunto de la maquinaria. Y este argumento era básico para quienes reclamaban la construcción de una red nacional ${ }^{13}$. No obstante, otras voces discrepaban e insistían en que la red tampoco constituiría por sí sola una panacea. De un lado, el cableado de la península era una inversión gravosa, que debería haber comprendido además otras auxiliares en el ciclo de generación y distribución ${ }^{14}$. De otro, la interconexión habría puesto a disposición de las compañías un excedente de energía en horas valle, las de menor consumo, cuyo aprovechamiento sólo sería viable mediante un plan de aumento de los empleos intensivos a gran escala, preferentemente a través de consumidores institucionales. Esta opinión pesimista fue la que finalmente se impuso y, pese a establecerse consultas en sucesivas ocasiones, la intervención no convenció a ningún gobierno de la Monarquía, la Dictadura o la República.

Este artículo parte del desconocimiento que hasta ahora se ha tenido tanto del estado de la transmisión eléctrica en España como de los esfuerzos que Administración y particulares realizaron en esa dirección con anterioridad a la Guerra Civil ${ }^{15}$.

\footnotetext{
${ }^{11}$ Para Italia, Giannetti (1985, p. 85) y para Noruega, Thue (1992).

12 Antolín (1999, p. 443).

13 Este argumento fue recurrente en algunas de las propuestas de red nacional más intervencionistas, barajadas desde 1920. Véase, por ejemplo, Pérez del Pulgar (1920), Artiñano (1921), Montañés (1924) y Montañés (1935).

${ }^{14}$ De este parecer se mostraron las compañías a través de su Asociación y aquellos ingenieros que las representaron en los debates que se sucedieron durante los decenios de 1920 y 1930 . El proyecto de red presentado por la propia Asociación en Sintés y Vidal (1933, p. 450 y ss). Otras opiniones contrarias y bien informadas en períodos bien distintos son las de Errandonea (1935b), Sánchez Cuervo (1935) y Manuel Fernández Campos en AE-INI: leg. 253, carpeta 93, Índice 1.

${ }^{15}$ Los únicos antecedentes asoman en excelentes investigaciones regionales: Amigo (1992), Núñez (1992) y Carmona (1999). Recientemente Alfonso Herranz (2004) ha calculado el valor de la cuota de participación de las redes de transporte eléctrico en el stock de infraestructuras españolas durante el primer tercio del siglo XX.
} 
Se comienza con un repaso a la situación de los mercados eléctricos en 1935, comparando con los casos contrapuestos de Italia y Francia entre otros ejemplos. Se presenta evidencia acerca de su integración espontánea y de los intentos frustrados de intervención de los organismos públicos. Las secciones siguientes discuten la viabilidad económica de la propuesta en perspectiva comparada y el alcance de la oposición institucional. Por último, se concluye defendiendo que antes de la Guerra Civil española, y pese al indudable peso de las presiones institucionales, prevalecieron criterios de orden técnico y económico a la hora de evitar la intervención pública en el tendido de la red eléctrica.

\section{EL SECTOR ELÉCTRICO Y EL CICLO DE TRANSMISIÓN ANTES DE LA GUE- RRA CIVIL}

La electrificación española fue más lenta, a menor escala y menos intensiva que en otros países vecinos, como Francia e Italia. Desde 1901, aquí también se basó en el agua, y alcanzó a constituir un 25 por cien de la oferta energética en 1935 cuando el 90 por cien de la población española tenía acceso al servicio eléctrico, pero los consumos eléctricos por habitante suponían un tercio del italiano y un quinto del francés ${ }^{16}$. Su comienzo tardío se explica por las condiciones geográficas del territorio español, que obstaculizaron la difusión temprana y masiva de sus aplicaciones más intensivas. El parque hidráulico español creció a buen ritmo, aunque asociado a los empleos manufactureros -a usos irregulares que lastraban los rendimientos del conjunto de la maquinaria-, pero desde 1925 se desaceleró. Las condiciones naturales de los saltos disponibles en la segunda mitad de los veinte urgían para su explotación la construcción de grandes diques que regularizasen por completo el caudal de los ríos. El aumento previsible de los costes de instalación no encajaba con un perfil de consumo donde los usos ligeros -iluminación y manufactura- eran los que más crecían. El incremento de estos empleos, coincidente con los períodos de punta del sistema, podía exacerbar aún más las necesidades de aumento del equipo de generación. En consecuencia, se daba la paradoja de que el patrimonio productivo de las empresas españolas presentaba bajos rendimientos -sobrepasando a duras penas las 2.500 horas de utilización del equipo hidráulico en 1935-, mientras que la maquinaria garantizaba con dificultad la continuidad del servicio en las horas punta, como se desprende de la columna 4 del Cuadro A-1. Aun cuando las compañías españolas empleaban a

${ }^{16}$ Estas cifras están basadas en mi estimación Bartolomé (1999), comparando con los datos de Etemad y Luciani (1991). Una aproximación sucinta al sector eléctrico en este período en Sudrià (1990) y los efectos dinámicos de esta industria sobre la economía española en Sudrià (1997). 
fondo su equipo productivo, incurrían en costes unitarios de explotación muy elevados ${ }^{17}$.

Según la teoría hegemónica desde 1945, la integración del mercado eléctrico y la regulación del ciclo de transmisión habrían contribuido a romper este círculo de hierro de la electrificación española, procurando cubrir las puntas de máxima demanda sin recurrir a nuevas construcciones y mejorando el rendimiento del conjunto de la maquinaria ${ }^{18}$. No obstante, ninguna autoridad impulsó efectivamente la coordinación del conjunto del mercado eléctrico español antes de 1936, cuando la interconexión entre compañías era aún muy desigual. La extensión temprana de redes de alta tensión había sido pionera entre los países de predominio hidroeléctrico, pero su densidad era baja y mostraba la debilidad de la integración, circunscrita a los subsistemas más desarrollados.

\section{CUADRO 1}

\section{PRIMEROS TRANSPORTES DE ELECTRICIDAD EN ESPAÑAA ELEVADA POTENCIA EN CORRIENTE ALTERNA}

(La longitud en km y la potencia en Voltios)

\begin{tabular}{|l|l|l|c|c|c|}
\hline Origen & Destino & Compañía & Año & Longitud & Potencia V \\
\hline Carcavilla & Zaragoza & ER Zaragoza & 1904 & 73,0 & 30.000 \\
\hline Leizarán II & Bilbao & H Ibérica & 1905 & 76,5 & 30.000 \\
\hline Guadiaro & Sevilla & Sevillana & 1905 & 125,0 & 50.000 \\
\hline Subterránea & Barcelona & Catalana G y E & 1905 & 12,0 & 50.000 \\
\hline Molinar & Madrid & H Española & 1909 & 254,0 & 66.000 \\
\hline Capdella & Barcelona & EE Cataluña & 1913 & 150,0 & 80.000 \\
\hline Tremp-Camarasa & Barcelona & RRFF Ebro & 1914 & 161,0 & 110.000 \\
\hline Camarasa & Serós & RRFF Ebro & 1914 & 62,0 & 110.000 \\
\hline Serós & Barcelona & RRFF Ebro & 1917 & 157,0 & 110.000 \\
\hline Seira & Barcelona & RRFF Ebro & 1922 & 224,0 & 110.000 \\
\hline Lafortunada & Bilbao & H. Ibérica & 1923 & 289,0 & 132.000 \\
\hline Molinar & Madrid & H. Española & 1926 & 254,0 & 132.000 \\
\hline Esla & Madrid/Bilbao & Saltos Duero & 1933 & 700,0 & 150.000 \\
\hline
\end{tabular}

Fuente: Bartolomé (2003, Anexo 1)

\footnotetext{
${ }^{17}$ Singularmente, por el recurso a las reservas térmicas en las puntas. Bartolomé (2003, cap. 2).

${ }^{18}$ Pese a que Milward (2004) se empeñe en evaluar el éxito de la integración en términos de aumento de la producción eléctrica, el rendimiento del aparato productivo constituye el indicador válido.
} 
Para empezar, la normalización técnica de los mercados españoles era deficiente: la legislación no entorpeció el despliegue de las líneas de transporte y distribución, garantizando su homologación, pero la heterogeneidad era el factor predominante ${ }^{19}$. Respecto de la transmisión, aparte de algunos transportes anteriores consignados por la prensa técnica, la primera gran línea de energía eléctrica fue la que unió en 1904 la central de Carcavilla con la subestación de San Gregorio en Zaragoza $^{20}$. Según se sigue de la cronología de la puesta en servicio de las principales líneas a alta tensión en el Cuadro 1, la máxima tensión alcanzada hasta 1923 era de 110 kV. En ese año, para 2.200 km de tendido de alta tensión en uso en España, 350 correspondían a líneas de 30 kV, 200 a líneas de 50 kV, 500 a 66 kV, 500 a 80 kV y 650 a 110 kV. A partir de ese año, con la terminación del Salto del Cinca en Huesca se puso en servicio la línea Lafortunada-Bilbao por parte de Hidroeléctrica Ibérica con 289 km de longitud a 132 kV, siguiendo en 1926 Hidroeléctrica Española con la modificación de la línea de transporte del Molinar a Madrid, que fue la primera en atravesar el centro de la península con características similares a las de Lafortunada. En 1935, con la inauguración de las líneas de Saltos del Duero, el Centro y el Norte peninsular se conectarían por vez primera, sumando entonces los cables erigidos de tensión mayor de $100 \mathrm{kV}$ los $3.050 \mathrm{~km}$, de los que 1.772 correspondían a aquellas de 110 y 1.278 a las de $132 \mathrm{kV}$, la mayoría con tendido doble ${ }^{21}$.

La alta tensión se había difundido en España con celeridad. Si se compara la cronología del tendido de las líneas de transmisión en España con la italiana y la francesa, no se apreciará entre ellas diferencial alguno de contemporaneidad, aunque la densidad de estas redes en Francia era mayor: en 1927 se habían tendido allí más de 110.000 km de cable para transporte y en 1933 más de 225.000 km, cuando en España en 1935 la suma de redes dedicadas al transporte y la distribución apenas superaban los $33.000 \mathrm{~km}$, las primeras reflejadas en el Cuadro $2^{22}$. Las líneas de alta tensión, singularmente aquellas que superaban los $120 \mathrm{kV}$, sumaban

\footnotetext{
${ }^{19}$ El primer Reglamento de 15 de junio 1901 fue sustituido por otros hasta llegar al definitivo de de 5 de julio de 1933. García Rodrigo (1927, pp. 5 y ss). Este problema, no obstante, era común a otros países, tal y como demuestran las Conferencias de la Energía. Segreto (1993). En España, este asunto ha sido abordado por Núñez (1995).

${ }^{20}$ Germán (1990).

${ }^{21}$ Las discrepancias entre las cifras del texto y las del Cuadro 2 se deben a que este último incluye también aquellas líneas de transmisión con voltaje inferior a $100 \mathrm{kV}$. Véase Sirvent, Mouton y de la Fuente (1960, pp. 3379 y ss).

${ }^{22}$ La primera línea de alta tensión francesa data de 1897 a una tensión de 10 KV. En 1898 se inauguró la primera de $15 \mathrm{kV}$ y en 1903 la primera de 26. En 1909 se tendió la pionera de $60 \mathrm{kV}$ y hasta 1922 no se inauguró un cabo de más de $100 \mathrm{kV}$, exactamente 120 , entre Beaumont-Monteux a Saint-Etienne et Saint-Chamond. Morsel (1991, p. 612). En el caso italiano, se adoptaron tensiones a $20 \mathrm{kV}$ en 1909, a $60 \mathrm{kV}$ en 1906, a $80 \mathrm{kV}$ en 1910, a 120 $\mathrm{kV}$ en 1923, a $150 \mathrm{kV}$ y a $220 \mathrm{kV}$ a partir de 1929. Giannetti (1991, p. 373).
} 
en Francia más de 7.000 km y en Italia 11.000, cuando en España sólo alcanzaban $\operatorname{los} 1.200^{23}$.

\section{CUADRO 2}

LÍNEAS DE TRANSPORTE EN ESPAÑA EN 1935

\begin{tabular}{|l|c|c|}
\hline Región & Líneas de transporte en km & Líneas en metros por km $\mathbf{~}^{2}$ \\
\hline Cataluña & 1607,14 & 49,92 \\
\hline Aragón & 214,30 & 4,52 \\
\hline Vasco-Navarra & 520,00 & 29,54 \\
\hline Astur-Santander & 624,00 & 38,18 \\
\hline Galicia & 269,00 & 9,23 \\
\hline Castilla & 801,00 & 8,05 \\
\hline La Mancha & 858,00 & 11,84 \\
\hline Extremadura & 519,00 & 12,47 \\
\hline Andalucía & 1456,62 & 16,69 \\
\hline Levante & 1789,00 & 36,21 \\
\hline Baleares & 31,00 & 6,18 \\
\hline Total & $\mathbf{8 6 8 9 , 0 6}$ & $\mathbf{1 7 , 4 5}$ \\
\hline
\end{tabular}

Fuente: COPDE (1935).

Así, y pese a que en torno a 1935 la transmisión eléctrica contara en España con un segmento técnicamente avanzado, los sistemas de interconexión continuaban siendo elementales. Según refleja el Cuadro 2, persistían islotes eléctricos apenas integrados en las rutas de las grandes compañías servidas por transmisiones en baja tensión. Las líneas principales que coordinaban efectivamente mercados eran la línea Este-Oeste de Lafortunada, que acercaba los mercados catalán y vasco, y la conexión Norte-Sur de Saltos del Duero, a través de Valladolid y Madrid, que conectaba el mercado vasco con el levantino. Los mercados periféricos, Cataluña y el País Vasco, eran los principales centros de consumo, a los que se dirigían, por tanto, los cables principales desde las cuencas productoras más destacadas, el valle del Ebro y la Cordillera Cantábrica. Los mercados madrileño y

${ }^{23}$ Francia en Lanthier (1994, p. 61). Advierto que este indicador, junto a la densidad de las líneas, puede conducir a error: de hecho, en 1938 en Italia, la alta tensión estaba más extendida que en Francia tanto en longitud total como en su densidad territorial; sin embargo, cuando en Francia se estaban realizando conexiones con la intención de integrar cargas entre el Noroeste y el Sureste, en Italia en su mayoría eran líneas de transporte. Milward (2004, p. 28, tabla 3). 
valenciano recibían buena parte de su energía desde las vertientes del Júcar y del Tajo. Mientras que Andalucía y la Galicia costera se coordinaban internamente, ambas Castillas y Extremadura apenas participaban de las líneas de las compañías suministradoras importantes, apreciándose una dualidad en la transmisión eléctrica en España, con unas áreas integradas y otras marginales.

Entretanto, los rendimientos del parque hidráulico español eran escasos, según revelan el recurso constante a las térmicas de reserva y el elevado porcentaje de pérdidas. Las reservas térmicas eran en su mayoría antiguas plantas centrales. Suplían las interrupciones de la central hidroeléctrica por fallos en la línea de transmisión. Se alcanzaban así los picos de la curva de consumo, cuando no bastaba la energía de la central hidráulica por estiaje, o para facilitar el desarrollo del mercado mientras se ampliaba la capacidad con nuevos generadores o con una nueva central. Las de mayor dimensión se emplazaban en Barcelona, Sevilla y Madrid, allí donde el consumo era mayor y las oscilaciones productivas hidráulicas debían subsanarse de inmediato. Cuando en Italia la potencia térmica disponible en 1936 apenas constituía un 20 por cien, en España suponía un creciente 30 por cien de la capacidad total de generación, aunque su uso mostrara fuertes oscilaciones. Su rendimiento en un año medio, como 1935, arrojaba el siguiente balance: si bien la potencia térmica ascendía a un 25 por cien del total, su producción oscilaba en torno al ocho por $\operatorname{cien}^{24}$.

Las pérdidas componían, a su vez, un importante capítulo: más de un 13 por cien de la producción al comenzar el siglo, para mantenerse alrededor del 20 por cien como media anual hasta 1935, fecha en que alcanzaron casi un 25 por cien ${ }^{25}$. No es de extrañar que, en la medida en que los puntos de explotación y los de consumo se distanciaron, aumentase la diferencia entre el volumen de la producción y el que los receptores empleaban. Asimismo, la pervivencia de buena parte de las redes primitivas de distribución en la mayoría de los núcleos urbanos se sumó a estos factores ${ }^{26}$. Sin embargo, la singular escasez de usos intensivos a pie de salto en España -electrosiderurgia y electroquímica- impuso un volumen adicional de pérdidas, ausente en otros sistemas hidráulicos con abundancia de estos empleos, como el italiano ${ }^{27}$.

Ante ese panorama, el tendido de una red nacional cundió como lema de la literatura técnica eléctrica durante los dos decenios anteriores a la Guerra Civil

${ }^{24}$ Concretamente 700 horas en 1934. COPDE (1935).

${ }^{25}$ INE (1949) e INE ( 1961) y Cuadro 4.

${ }^{26}$ Pese a que la ausencia de normalización en tensiones y la convivencia de sistemas constituía un fenómeno bastante extendido en la Europa de entreguerras, parece que en algunas zonas españolas el fenómeno alcanzaba proporciones muy agudas. No sólo se favorecían así las pérdidas, sino incluso el fraude por parte de los usuarios. Véase De la Fuente (1908, p. 123). La escasa homologación de la distribución en Núñez (1995).

${ }^{27}$ Véase Bartolomé (2003, cap. 2). 
española, aunque su ejecución se presentase con enormes dificultades. El propio Estado abrió sucesivas consultas para examinar la conveniencia de erigir esta red. La primera coincidió con el final de la Gran Guerra y el desencadenamiento del «problema ferroviario» en España. Una de las alternativas, la sustitución del equipo móvil convencional por equipo móvil eléctrico alentó el debate sobre la conveniencia del tendido simultáneo de una red de transporte de energía que abasteciera la red de ferrocarriles e integrara los mercados eléctricos peninsulares. En 1918, desde la Dirección General de Comercio, Industria y Trabajo se solicitó a la Comisión Permanente Española de Electricidad (CPEE) un proyecto acerca de una intervención del Estado en la distribución de la energía eléctrica con la excusa de la unificación de las tensiones ${ }^{28}$. Este Dictamen despertó un debate técnico que se mantuvo vivo durante varios años, en particular entre los ingenieros. La segunda se suscitó con la movilización prebélica, que ligó la explotación de los carbones a bocamina, la red y la fabricación de productos nitrogenados. Se abrió en plena Dictadura, cuando en 1926 se convocó un concurso de proyectos, pero la información relativa a las propuestas recibidas sufrió sucesivos retrasos que culminarían con su derivación al Consejo de la Energía en 1929, el cual jamás se pronunció al respecto ${ }^{29}$. La tercera ocasión fue en 1935, en la Segunda República, durante la información pública del estudio sobre «La Economía de las Obras Hidráulicas» que la Comisión Gestora del Consejo Ordenador de la Economía Nacional había encomendado a José Larraz ${ }^{30}$. Por último, en plena guerra y en el bando nacionalista, la Delegación de Servicios Técnicos de la FET y de las JONS elaboró un cuestionario exhaustivo para informar la «Ponencia General de Red y Ordenación Eléctrica Nacional», respondido al menos por Manuel Fernández Campos ${ }^{31}$.

La evolución de éstas y otras propuestas muestra una deriva que va desde el decidido intervencionismo público de los primeros proyectos, como el de la CPEE o el de los ingenieros Berasaluce y Mayoral, a una progresiva desconfianza en el papel de los organismos estatales en la financiación y el control de la red, como reflejaba el proyecto de Fernández Campos. Al contrario que en otros países europeos, el sector eléctrico parecía alejarse progresivamente del discurso de «movilización nacional» que alentaba los ambientes técnicos en los primeros trein-

\footnotetext{
${ }^{28}$ Sus únicos precedentes eran el artículo que había publicado el Padre Pérez Del Pulgar en 1915 en la revista Ibérica y las sugerencias al respecto de Juan Urrutia en su segunda entrega de La Energía Hidroeléctrica, aquel mismo año de 1918. Pérez del Pulgar (1915, p. 411) y (1917) y Urrutia (1918). El proyecto en Proyecto (1919).

${ }^{29}$ El procedimiento se dilata entre la Real Orden de 9 de junio de 1926 (Gaceta del 24) y el Decreto de 11 de junio de 1928 (Gaceta del 19). Pero, de hecho, cesa la intervención. La narración, por extenso, en Bartolomé (2003, cap. 3).

${ }^{30}$ Se preveía que sus conclusiones tuvieran un carácter meramente consultivo. Castel (1936, pp. XXXIX y XL).

${ }^{31}$ Manuel Fernández Campos había sido secretario en 1930 de Sevillana de Electricidad, según AFSAE (1930). La propuesta en AE-INI: Leg. 253, carpeta 93, Indice 1.
} 
$\mathrm{ta}^{32}$. En definitiva, los procedimientos administrativos abiertos no progresaron y la integración del mercado eléctrico, y el control centralizado de sus cargas, descansó sobre las compañías, debiendo esperar casi medio siglo para hacerse efectiva.

\section{LOS FACTORES INSTITUCIONALES EN LA CONSTRUCCIÓN DE LA RED}

En 1970, se planteó por primera vez en España el malogro del proyecto de red eléctrica como problema historiográfico. Aunque la cuestión no haya empezado a responderse hasta muy recientemente, siempre se ha comulgado con el sentir general de la historiografía italiana, que considera que en aquel país se perdió una importante oportunidad con la frustración de la red nacional ${ }^{33}$.

Esta literatura se ha inclinado por explicaciones de corte institucional para justificar el retraso en la interconexión de los mercados eléctricos. Y esta preferencia no es casual. Deriva, en primer término, del tenor de las fuentes internacionales coetáneas, que defienden que la construcción de las redes nacionales constituyó un escalón más en la intervención de los mercados eléctricos por parte del Estado $^{34}$. Desde la perspectiva del nacionalismo de entreguerras, se consideraba el territorio nacional como un input global y sus recursos, por tanto, gestionables centralizadamente. Con la financiación pública del tendido de la red se favorecería tanto el autoabastecimiento como la integración energética del territorio. Atendiendo a esta lógica, allí donde la red no se erigió se indicaría que la Administración carecía o bien de apoyo o bien de capacidad financiera para intervenir ${ }^{35}$. Pero este sesgo institucional obedece, en segundo término, a la evidente oposición al tendido de las redes que mostraron las empresas que disfrutaban de monopolios regionales ${ }^{36}$. En esta lectura, las estrategias conservadoras de las compañías serían las responsables del retraso en el tendido de sus redes nacionales. Giannetti (1985, p. 84) ha apuntado que, en pro de la supervivencia de los sistemas regionales italianos, las compañías obstruyeron largamente cualquier iniciativa de erección de una «dorsal» que integrara sus distintos mercados. Las relaciones y diferentes estrategias de las empresas internacionales electrotécnicas que financia-

\footnotetext{
${ }^{32}$ Entre los primeros me refiero a Proyecto (1919), y Berasaluce y Mayoral en Congreso Nacional de Ingeniería (1919); entre los segundos, destaca la oposición de Sánchez Cuervo (1935), pero también la de Fernández Campos en AE-INI: Leg. 253, carpeta 93, Indice 1. La excepción es Montañés (1935), quien vinculado desde sus orígenes en Barcelonesa a la Canadiense defendía en 1935 los postulados más intervencionistas.

${ }^{33} \mathrm{Al}$ profesor Nadal cabe el mérito de haber llamado la atención sobre la red eléctrica como problema historiográfico. Nadal (1970, p. 405). Italia en Giannetti (1995) у (1997).

${ }^{34}$ Como así defiende en su análisis Milward (2004).

${ }^{35}$ Para su seguimiento en las Conferencias Mundiales de la Energía, véase Segreto (1993). La principal aportación española, Montañés (1924).

${ }^{36}$ Sin olvidar otros contendientes, como distribuidoras y consistorios locales. Milward (2004).
} 
ban los diversos sistemas regionales, y las propias dificultades de financiación provocadas por la estabilización de la lira mediado el decenio de 1920, habrían postergado el plan. Pese a las disposiciones a favor del tendido de líneas a gran potencia, los proyectos se ejecutarían durante la post-guerra mundial. Francesca Antolín (1999) ha establecido un paralelismo entre el caso italiano y el español. Considera una oportunidad perdida la escasa intervención pública en esta materia, que obedecería, a su juicio, al temor de las compañías eléctricas a una integración de mercados que pusiera en peligro la posición precio-determinante de que disfrutaban gracias al aislamiento. La pasividad de los organismos públicos sería atribuible a su captura por parte de las empresas eléctricas ${ }^{37}$. A favor de este argumento se podría añadir que, en algunos países, la participación pública en el tendido de las redes nacionales de interconexión coincidió con las ayudas que recibieron las eléctricas para levantar infraestructuras de almacenamiento de agua. La concurrencia de ambos procesos entre 1925 y 1946 induciría a pensar que las empresas habrían presionado a la Administración para que contribuyese a la construcción de presas y embalses, pero se habrían empleado en evitar que los mercados regionales desregulados se vieran intervenidos con el tendido de la red. La coincidencia de intereses, cuando no connivencia, entre políticos y empresarios durante estos años parecería indudable ${ }^{38}$.

Ahora bien, estas explicaciones estrictamente institucionales colisionan con la comparativa europea de R. Milward (2004), quien quizá involuntariamente ha revelado cómo el tendido de la red se efectuó en entornos institucionales bien distintos. A mi juicio, y como se desglosa en las siguientes secciones, la naturaleza de los recursos primarios empleados en la obtención de electricidad y la composición de los equipos de generación constituyeron los criterios decisivos a la hora de determinar el futuro de la red de interconexión en un territorio durante el período de entreguerras. De hecho, el caso español se inscribe en el conjunto de los países hidroeléctricos que, exceptuadas Suecia y Suiza, descollarían poco en el tendido de redes nacionales antes de 1945. La principal razón estriba en que los bajos rendimientos afectaban más severamente a los sistemas térmicos, como el alemán o el británico -con utilizaciones en torno a un 20 por cien y predominio de empleos discontinuos-, además de carecer de alternativa para la mejora de la eficiencia de su maquinaria ${ }^{39}$. En muchos países hidrodependientes, los rendimientos de los sistemas comerciales eran elevados y los sistemas regionales consti-

\footnotetext{
${ }^{37}$ Argumentos que nutren lo que de España dice Milward (2004, pp. 8 y ss).

${ }^{38}$ Así se ha puesto de manifiesto para el caso italiano. Giannetti (1997). En España, hay que recordar que la ayuda española a la construcción de diques fue escasamente efectiva, en Bartolomé (2003, cap. 3).

${ }^{39}$ Myllintaus ofrece cifras de utilización en diversos países y para el período 1925-33 en las que Gran Bretaña, Alemania, y también Francia, salen muy mal paradas, con utilizaciones que no superan el 20 por cien. Myllintaus (1991, p. 212).
} 
tuían por sí mismos islotes eléctricos autosuficientes, que incluían tanto grandes infraestructuras de generación como la diversidad de los consumos que se buscaba en las redes de coordinación a gran escala ${ }^{40}$. Aún así, el tipo de centrales y la diversidad en la composición de los sistemas regionales influyeron también de diversas maneras en el nivel que alcanzaría la interconexión de los mercados hidroeléctricos. No quiere esto decir, obviamente, que la capacidad inversora de la Administración y el grado de legitimidad institucionales de los organismos interventores fueran factores totalmente ajenos a la construcción de la red en el decenio de 1930. No fue así, aunque convenga recordar que las empresas italianas, por ejemplo, habían aceptado otras regulaciones públicas -sobre precios, mercados locales y subvenciones-, de manera que la gestión de la red podría haber adquirido formas diversas, si sólo hubieran sido barreras institucionales las que se interpusieran en su ejecución ${ }^{41}$.

\section{UNA PERSPECTIVA TÉCNICO-ECONÓMICA: EL MODELO FRANCÉS VS. EL ITALIANO}

En primera instancia, parece que en los entornos hidroeléctricos como el italiano o el español los grandes establecimientos de generación dotados de embalse revestían más interés que la interconexión de mercados cuando se perseguía allegar fluido al menor coste. Esto es, como ambas infraestructuras eran muy gravosas, allí donde se optó por construir y subvencionar diques, como en Italia y brevemente en España, se habría sustituido una infraestructura por otra, redes por presas $^{42}$. Mientras, en territorios térmicos, como el británico o el alemán, o con menores necesidades de regulación de caudales como en Suiza, se habría agilizado el proceso del cableado en alta tensión, en tanto ni Estado ni compañías tendrían que asumir el coste de otras infraestructuras.

Esta interpretación sería, además, la más coherente con la literatura económica de la segunda mitad del siglo XX, donde los sistemas de coordinación se presentan como inversiones alternativas al incremento de la capacidad de generación. Desde 1925, en Italia y España el coste de oportunidad de financiar la red nacional habría sido menor que el de incrementar la disponibilidad de energía a través de centrales de generación: únicamente se habrían tendido mallas cuando el coste de obtener un kWh adicional mediante la construcción de una central superase al de su acceso vía interconexión ${ }^{43}$. Como los costes de las centrales de generación

\footnotetext{
${ }^{40}$ Para Italia, Giannetti (1991, pp. 354 y ss). Thue (1992) señala que en Noruega predominaba la autogeneración y las redes locales.

${ }^{41}$ Giannetti (1997, p.132).

${ }^{42}$ Las subvenciones a las presas, para Italia, Ottolino (1993); España, Bartolomé (2003, cap. 3).

${ }^{43}$ Esta lógica nutre la mayoría de las monografías de «Economía de la Energía» desde 1945. Peirce (1996).
} 
en los países hidrodependientes eran entonces directamente proporcionales al tamaño y a la necesidad de regulación de caudales, las ventajas de la interconexión aumentarían cuando se coordinasen pequeñas centrales con diferentes regímenes de generación -según naturaleza o régimen hidráulico- y cuanto más se integraran diferentes perfiles de demandantes. Así, cuanto más diversos fueran los subsistemas eléctricos de un territorio y menores los aprovechamientos que debieran construirse, mayor sería la probabilidad de que un eventual planificador se inclinara por incrementar la capacidad de un sistema mediante el tendido de una red. Esta es la lógica, por ejemplo, de la interconexión sueca, donde los recursos del Norte se integraron con los consumidores del Sur ${ }^{44}$.

Ahora bien, esta noción de integración como alternativa a la generación contrasta con algunos fenómenos propios del primer tercio del siglo XX. Giannetti (1985, pp. 84 y ss) ha mostrado el carácter complementario de ambos tipos de infraestructuras en sistemas eléctricos en intenso crecimiento: las redes sólo eran económicamente viables cuando los aprovechamientos coordinados y la carga transportada alcanzaba un valor medio elevado ${ }^{45}$. Este autor, el mismo que considera que la construcción de las redes podría haber procurado importantes ventajas a las compañías italianas si se hubieran integrado, insiste en las particularidades de los sistemas de naturaleza hidráulica. El problema inicial era, a su juicio, la financiación de un proyecto que presentaba costes irrecuperables, y cuya rentabilización inmediata se avenía muy poco con la especificidad de los sistemas hidrodependientes: las redes de alto voltaje debían coordinar las cargas entre centros técnicamente análogos para evitar pérdidas en el transporte. Mientras que en Inglaterra o Alemania los sistemas térmicos se constituyeron en torno a vértices que albergaban grandes núcleos productores, los sistemas hidráulicos, como el italiano, aprovechaban recursos dispersos y de muy diversa escala -minúsculas centrales fluyentes junto a macrocentrales. En estos sistemas además la construcción de grandes centrales estaba gravada por costes de instalación que aumentaban exponencialmente respecto al tamaño del aprovechamiento y presentaban indivisibilidades técnicas ${ }^{46}$. Los países hidráulicos se enfrentaban, pues, al doble reto de homologar núcleos de generación y líneas de transmisión. Los grandes sistemas de interconexión a escala interregional serían, por tanto, propios de sistemas eléctricos necesitados de mejorar sus rendimientos, pero maduros e integrados técnicamente: aquellos constituidos por grandes centrales desde las que se transmiten grandes cargas constantes a voltajes elevados ${ }^{47}$. Por tanto, antes

\footnotetext{
${ }^{44}$ Suecia en Kaijser (1987, pp. 17-21).

45 Esto se sabía con claridad en los primeros treinta. Mortara (1934, p. 477).

${ }^{46}$ Los sistemas térmicos crecían acumulativamente, mientras los hidráulicos lo hacían abruptamente. Turvey (1971).

${ }^{47}$ Giannetti (1985, p. 132).
} 
de 1945, el tendido de redes de coordinación en los sistemas dependientes del agua sería un proyecto vinculado, y no alternativo, a aquellos destinados a aumentar la capacidad de generación mediante hipercentrales.

Durante los años treinta, los ejemplos francés e italiano confirman estas hipótesis. En ambos países se avanzó hacia la constitución de sistemas eléctricos maduros, por cuanto se construyeron centrales cada vez de mayor tamaño con apoyo público y se incrementaron tanto la carga de las centrales como los voltajes de los transportes ${ }^{48}$. Sin embargo, dos características propias del sistema francés lo convertían en propicio a disfrutar las ventajas de la interconexión. La fundamental era la escisión en dos zonas de generación completamente diversa -el noroeste dependiente del carbón y el sudeste definitivamente hidrodependiente ${ }^{49}$. La circunstancial fue la tendencia denunciada por los contemporáneos a construir hipercentrales, favorecida por la política de subvenciones de los últimos años veinte y treinta. Este último rasgo lo compartía con Italia, pero las ventajas derivadas de la interconexión en esa península podían resolverse con integraciones a menor escala, puesto que la diversidad en los sistemas de generación, de naturaleza hidráulica, se solventaba con la coordinación de centrales de régimen de estiaje apenínico con aquellas de régimen alpino ${ }^{50}$. Todo indicaría, pues, que las características técnicas del sistema francés espoleaban en mayor medida que en Italia la construcción de una red nacional, sin olvidar que mercados tan definidos y compañías tan implantadas como las italianas no facilitarían, en absoluto, una intromisión de esta naturaleza.

\section{EL PECULIAR SISTEMA HIDRÁULICO ESPAÑOL: BAJOS RENDIMIENTOS Y CONSUMOS IRREGULARES}

Los indicadores de eficiencia de las instalaciones eléctricas españolas empujaban a favor de la red. En primer lugar, el rendimiento de los equipos, medido tanto de horas de utilización de la potencia hidráulica instalada como de «factor utilización», era menor en cinco puntos de aquel que presentaban los países hidrodependientes que empleaban intensivamente la electricidad, como Finlandia o Suecia en 1935. Según desvela el Cuadro A-1, el promedio de horas de utilización de las centrales hidráulicas españolas aún no alcanzaba las 3.000 horas, o lo que es lo mismo, en torno a un 35 por cien de utilización de la potencia según la

\footnotetext{
${ }^{48}$ La discusión sobre la cuantía y el alcance de las ayudas francesas en Levy-Levoyer (1994, pp. 108 y ss).

${ }^{49}$ Esta circunstancia se reforzó cuando a partir de 1936 el coste de las inversiones en cada nuevo kW instalado de origen hidráulico aumentaba más rápidamente que el precio del carbón importado. Lévy-Levoyer (1994, p. 111).

${ }^{50}$ Giannetti (1985) y (1997).
} 
columna 6, cuando en aquellos países ya se superaba el 40 por cien ${ }^{51}$. Además, según las columnas 8 y 9 del mismo Cuadro, las horas de utilización eran en promedio semejantes en los establecimientos grandes y en los pequeños y las diferencias regionales eran menos ostensibles que en otros apartados. Esto significa al cabo que el rendimiento del sistema eléctrico español era similar al calculado para países térmicos, lo que supondría un estímulo vigoroso para la construcción de la red. En segundo lugar, el factor carga calculado en la columna 5 del Cuadro A-1 era elevado, rondando casi el 40 por cien, debido a la prevalencia de empleos que elevaban la punta de la demanda, como la manufactura y la iluminación. Asimismo, la carga máxima instantánea de las centrales -que aparece en la columna 4 del mismo Cuadro- muestra valores muy crecidos, lo que abundaría en la idea de que algunos subsistemas hidráulicos relevantes eran incapaces por sí mismos de garantizar la cobertura del sistema, y de que el resto se encontraba también muy cerca de ese límite. Ambos constituían evidentes alicientes a la coordinación: este «factor carga» indicaba que, pese a su baja utilización, se obtenía una rentabilidad del capital invertido nada desdeñable y que, en teoría, la red habría contribuido a solventar la cobertura de las instalaciones sin el recurso a las térmicas y evitando la construcción de nuevas centrales.

Ahora bien, los incentivos a la interconexión eran escasos desde el punto de vista de la diversidad de los medios de generación y de los perfiles de demanda. Los subsistemas españoles eran muy homogéneos a diferentes escalas. La generación era básicamente hidrodependiente con regímenes hidráulicos ligeramente diversos, cuya heterogeneidad era a menudo aprovechada en el marco del propio subsistema. En efecto, en España predominan los regímenes fluviales de máximos en otoño e invierno, debido a su dependencia pluvial, con escasas aportaciones nivales -al final de la primavera- en el entorno pirenaico, que se aprovechaban en los subsistemas catalano-aragonés y vasco ${ }^{52}$. Esto se refleja en el Cuadro 3, donde se observa que los picos de las centrales españolas, al margen de su tamaño, coincidían con los meses de diciembre y enero, los períodos junto con noviembre de consumos más elevados ${ }^{53}$.

La demanda era irregular en todos los subsistemas. Los usos domésticos habían ido cediendo paso a los manufactureros, pero arrastraban elevados porcen-

\footnotetext{
${ }^{51}$ Los datos para Italia son de factura compleja, pues en los cálculos del sistema comercial se estima una utilización del 28 por cien en 1933 y unas 3.000 horas de utilización, pero si se incluyen los aprovechamientos intensivos no integrados en aquellas redes, Giannetti eleva el rendimiento a las 5.000 horas. Para Escandinavia, Millyntaus (1991, p. 212); para Italia, Giannetti (1985).

52 Lorenzo Pardo realiza ya en 1933 un avance del estudio de estos regímenes con datos entre 1921 y 1939. Ministerio de Obras Públicas (1933, pp. 91 y 92).

${ }^{5}$ En Cataluña, 25 centrales -de un total de 43- alcanzaban sus máximos en los meses de otoño-invierno, mientras que 17 lo hacían durante la primavera. COPDE (1936).
} 
tajes de pérdidas como desvela el Cuadro 4. De hecho, las enormes diferencias en términos absolutos entre el consumo de fuerza en el País Vasco en 1935 -375 kWh por habitante y año-y en Castilla -que no sobrepasaba los 28 kWh- no se correspondía con porcentajes desequilibrados entre empleos: la fuerza industrial rondaba en todo el país entre el 80 y el 85 por cien de los consumos, si se excluían pérdidas, y los empleos intensivos apenas superaban el ocho por cien ${ }^{54}$.

\section{CUADRO 3}

\section{PORCENTAJE DE ESTABLECIMIENTOS HIDRÁULICOS QUE EN 1936 ALCANZABAN LA POTENCIA MÁXIMA EN CADA MES}

\begin{tabular}{|l|c|c|c|}
\hline $\begin{array}{c}\text { Mes } \\
\text { Potencia Máxima }\end{array}$ & $\begin{array}{c}\text { Todos los } \\
\text { establecimientos }\end{array}$ & $\begin{array}{c}\text { Establecimientos } \\
>\mathbf{5 0 0 0} \mathbf{~ k W}\end{array}$ & $\begin{array}{c}\text { Establecimientos } \\
<\mathbf{1 0 0 0} \mathbf{~ k W}\end{array}$ \\
\hline Enero & $13,64 \%$ & $8,51 \%$ & $13,68 \%$ \\
\hline Febrero & $2,78 \%$ & $4,26 \%$ & $2,81 \%$ \\
\hline Marzo & $4,29 \%$ & $2,13 \%$ & $3,16 \%$ \\
\hline Abril & $2,78 \%$ & $6,38 \%$ & $2,11 \%$ \\
\hline Mayo & $3,79 \%$ & $4,26 \%$ & $3,16 \%$ \\
\hline Junio & $3,79 \%$ & $6,38 \%$ & $2,11 \%$ \\
\hline Julio & $1,77 \%$ & $4,26 \%$ & $1,75 \%$ \\
\hline Agosto & $3,28 \%$ & $0,00 \%$ & $3,51 \%$ \\
\hline Septiembre & $2,78 \%$ & $6,38 \%$ & $2,46 \%$ \\
\hline Octubre & $3,54 \%$ & $2,13 \%$ & $4,21 \%$ \\
\hline Noviembre & $3,79 \%$ & $8,51 \%$ & $3,16 \%$ \\
\hline Diciembre & $18,69 \%$ & $21,28 \%$ & $19,30 \%$ \\
\hline Sine Data & $34,34 \%$ & $23,40 \%$ & $38,59 \%$ \\
\hline Sostenida & $0,76 \%$ & $2,13 \%$ & $0,00 \%$ \\
\hline Total General & $\mathbf{1 0 0 , 0 0 \%}$ & $\mathbf{1 0 0 , 0 0 \%}$ & $\mathbf{1 0 0 , 0 0 \%}$ \\
\hline
\end{tabular}

Fuente: COPDE (1936).

A imitación de los ejemplos alemán y británico, la red eléctrica nacional podría haber ayudado a mejorar los rendimientos tanto del equipo de transmisión, que incurría en graves pérdidas, como de aquel de generación, sobre-explotado. Se habría evitado así además la inversión en nuevas centrales eléctricas que alteraran a la baja el «factor carga» del sistema eléctrico español. Sin embargo, esta emulación era inviable: el sistema español dependía del agua y el buen uso de la red demandaba la construcción ineludible e indivisible de macro-centrales, que era, justamente, la inversión que se quería evitar con la interconexión.

\footnotetext{
${ }^{54}$ Según los datos que proporciona Vidal Burdils (1941).
} 


\section{CUADRO 4}

CONSUMO DE ENERGÍA ELÉCTRICA EN ESPAÑA POR TIPOS DE EMPLEO

\begin{tabular}{|l|c|c|c|c|c|}
\hline \multirow{2}{*}{ Año } & \multicolumn{6}{|c|}{ Consumos en porcentaje } \\
\cline { 2 - 6 } & Alumbrado & Tracción & Industria & Pérdidas & Total \\
\hline 1901 & 69,47 & 6,32 & 11,05 & 13,16 & $\mathbf{1 0 0 , 0 0}$ \\
\hline 1905 & 65,65 & 7,39 & 11,30 & 15,65 & $\mathbf{1 0 0 , 0 0}$ \\
\hline 1910 & 48,18 & 8,96 & 19,61 & 23,25 & $\mathbf{1 0 0 , 0 0}$ \\
\hline 1915 & 40,04 & 8,82 & 33,33 & 17,81 & $\mathbf{1 0 0 , 0 0}$ \\
\hline 1920 & 31,26 & 8,28 & 40,48 & 19,98 & $\mathbf{1 0 0 , 0 0}$ \\
\hline 1925 & 19,78 & 10,49 & 50,68 & 19,05 & $\mathbf{1 0 0 , 0 0}$ \\
\hline 1930 & 15,48 & 9,16 & 55,58 & 19,78 & $\mathbf{1 0 0 , 0 0}$ \\
\hline 1935 & 15,11 & 7,67 & 52,41 & 24,81 & $\mathbf{1 0 0 , 0 0}$ \\
\hline
\end{tabular}

Fuente: INE (1949) y ( 1961).

\section{CUADRO 5}

\section{KW HIDROELÉCTRICOS INSTALADOS POR REGIONES EN 1930}

\begin{tabular}{|l|c|c|}
\hline \multicolumn{1}{|c|}{ Región } & KW por $\mathbf{~ k m}^{\mathbf{2}}$ & KW cada 1.000 hab. \\
\hline Andalucía & 1,14 & 21,72 \\
\hline Aragón & 2,80 & 127,93 \\
\hline Astur-Santander & 4,19 & 58,14 \\
\hline Baleares & 0,16 & 2,28 \\
\hline Canarias & 0,05 & 0,63 \\
\hline Castilla & 0,74 & 27,50 \\
\hline Cataluña & 7,23 & 83,95 \\
\hline Extremadura & 0,14 & 5,05 \\
\hline Galicia & 1,15 & 15,22 \\
\hline La Mancha & 1,00 & 41,97 \\
\hline Madrid & 3,30 & 19,17 \\
\hline Murcia & 1,43 & 25,52 \\
\hline País Vasco & 5,19 & 73,65 \\
\hline Valencia & 1,95 & 24,20 \\
\hline Total General & $\mathbf{1 , 7 9}$ & $\mathbf{3 8 , 4 5}$ \\
\hline
\end{tabular}

Fuente: Bartolomé (2003, Anexo 1) y Carreras (1989) para la población. 
La densidad de los sistemas eléctricos españoles en 1930 era muy desigual tanto desde el punto de vista de la generación como de la distribución. Como desvela el Cuadro 5, la distribución de la potencia eléctrica era heterogénea: la geografía del aprovechamiento se atenía a la cercanía de mercados consumidores. Sólo superaban la media española de kW instalados cada 1.000 habitantes las regiones cantábricas, que nutrían sobre todo el mercado del País Vasco; Aragón y Cataluña, para servir a esta última; y la Mancha, a fin de suministrar al mercado madrileño. En Galicia y Extremadura, cuyo potencial hidráulico era elevado, se había explotado la energía cinética del agua aún en menor medida que en Murcia y en Valencia. La densidad de la potencia instalada por $\mathrm{km} 2$, desglosada en la siguiente columna, muestra a las claras el desierto eléctrico que constituyó todo el interior peninsular hasta la inauguración en 1933 de parte de los equipos de Saltos del Duero.

La concentración de la producción era evidente, en torno a centrales hidroeléctricas cada vez de mayor tamaño: de establecimientos con una media menor que $60 \mathrm{~kW}$ instalados en 1901, se había pasado a superar los 2.500 en 1935, como se presenta en el Cuadro A-1 $1^{55}$. Pese a estos logros, antes de la Guerra Civil todavía un veinte por cien de la potencia instalada lo era en centrales que contaban con menos de $5.000 \mathrm{~kW}$ de capacidad y solamente diez centrales superaban los $25.000 \mathrm{~kW}^{56}$. En el parque hidroeléctrico español de 1935 convivían grandes centrales en activo con otras pequeñas y dispersas, como se desprende de la potencia media regional de las centrales consignada en la columna 3 del Cuadro A-1: mientras en Cataluña el promedio por establecimiento rondaba los $5.000 \mathrm{~kW}$ instalados, en Galicia y Extremadura, importantes regiones productoras en la actualidad, la capacidad de las centrales no llegaba a los $1.000 \mathrm{~kW}$ en la primera y apenas los 200 en la segunda ${ }^{57}$. En la propia Cataluña se contabilizaban 53 establecimientos de condiciones muy diversas. Aun cuando la provincia de Gerona disponía de más centrales que aquella de Lérida, esta última albergaba un 93 por cien de la capacidad instalada en Cataluña con promedios mayores de $15.000 \mathrm{~kW}$, cuando los 25 aprovechamientos gerundenses recogidos en esta fuente promediaban los $600 \mathrm{~kW}^{58}$. En contraste, la potencia media de las centrales hidráulicas francesas instaladas entre 1901 y 1936 sobrepasaba los 12.700 kW y más de 14 centrales

\footnotetext{
${ }^{55}$ Las cifras proceden de mi estimación de las principales variables del sector eléctrico español, Bartolomé (1999).

${ }^{56}$ Las compañías más pequeñas escapaban a la disciplina de la Cámara de Productores y Distribuidores de Electricidad, pese a que ésta cubría un 90 por cien de la potencia instalada en territorio español.

57 De los 1.249.000 kW instalados en 1936, 956.900 lo eran en centrales mayores de $4.000 \mathrm{~kW}$. La capacidad de los aprovechamientos mayores de $25.000 \mathrm{~kW}$ alcanzaba en 1936 los 406.154 kW. Cálculos elaborados en Bartolomé (2003, Anexo cap. 1).

${ }^{58}$ La dispersión era aún mayor según el censo exhaustivo para Cataluña de Maluquer (1986).
} 
eran mayores de $50.000 \mathrm{~kW}^{59}$. A su vez, en algunos sistemas regionales italianos, como el piamontés, la media instalada por central multiplicaba hasta por cien el promedio español ${ }^{60}$.

En definitiva, en 1935 apenas se contaban algunos vértices análogos entre los núcleos productores españoles que pudieran conectarse automáticamente mediante la red nacional. La integración del mercado eléctrico debería haberse acompañado de la construcción de grandes centrales homologables, hidráulicas y/o térmicas a bocamina, además de asegurarse un mejor rendimiento del conjunto del nuevo sistema con la incorporación de nuevos usos intensivos -los llamados entonces consumidores institucionales- que emplearan la capacidad excedentaria vertida en las grandes líneas. De esta circunstancia se habían percatado los técnicos partidarios de una decidida intervención pública en el tendido de la red: o bien propusieron la electrificación de los ferrocarriles o la creación de industrias altamente consumidoras, particularmente la química del nitrógeno en los albores de la Guerra Civil ${ }^{61}$. Estos consumidores intensivos habían surgido espontánea y precozmente en los principales países hidrodependientes, como Noruega, Suecia o Suiza. Cuando éstos se incorporaban a las grandes redes aseguraban la utilización en horas valle de los equipos -máquinas generatrices y redes. Donde estos consumos no se habían promovido privadamente, a causa de su discutible rentabilidad, la inversión pública podía igualmente contribuir a garantizarlos ${ }^{62}$. La cobertura ideológica de la «autarquía» económica prestó un buen paraguas a estos postulados y en Portugal, por ejemplo, se decidió en los cuarenta acometer con participación pública los tres proyectos al mismo tiempo: construcción de la red, erección de diques y fabricación de abonos ${ }^{63}$. El coste del conjunto del proyecto en España -red más macrocentrales más fábricas o electrificación ferroviaria- era, sin duda, imponente, quizá disparatado dadas las posibilidades de la Hacienda española de aquellos años, y la rentabilidad de estas infraestructuras con costes hundidos no estaban en absoluto aseguradas. Sin considerar la construcción complementaria de diques para embalse de agua y la promoción de sus consumidores institucionales, el coste del cableado de la península, según el proyecto de mínimos de Diego Mayoral en 1921, se habría elevado a más de 250 millones de

\footnotetext{
${ }^{59}$ Morsel (1987, p. 102).

${ }^{60}$ Giannetti (1991, p. 360). A cambio, la mayoría de los establecimientos españoles participaba en las redes comerciales, la autogeneración era una excepción en España, sumando las centrales hidráulicas y térmicas de este tipo: $128.207 \mathrm{~kW}$ en 1936, menos de un 10 por cien de la capacidad total instalada en España. Sindicato Nacional de Agua, Gas y Electricidad (1960).

${ }^{61}$ Pérez del Pulgar (1920) , Montañés (1935) y Larraz, industria del nitrógeno, Castell (1936).

${ }^{62}$ La rentabilidad de los procesamientos eléctrico-industriales en España en Bartolomé (2003, cap. 2).

${ }^{63}$ Por extenso en la excelente síntesis de Madureira (2004), gentileza del autor.
} 
pesetas de haberse realizado en aquella fecha. Este presupuesto suponía más del doble del concedido para el auxilio de presas de uso eléctrico un decenio más tarde $^{64}$. A su vez, la rentabilidad de las fábricas de gran consumo eléctrico fue objeto de diversos estudios por parte de los coetáneos, entre los que destacan los de Esteban Errandonea, quien en 1935 divulgó la escasa viabilidad de la producción de nitrato de calcio en circunstancias de apertura comercial ${ }^{65}$. En realidad, la red devengaría en una pesada carga, pese a que el nacionalismo español de entreguerras la creyera «columna vertebral del porvenir industrial de España» ${ }^{66}$.

Antes de la Guerra Civil, sólo una decisión política de largo alcance a fin de procurar un conjunto de infraestructuras con capacidad inicial excedentaria, y a un coste elevado, podría haber alentado este proceso. Sólo la tozudez de un proyecto ultranacionalista, como el presentado por Pérez del Pulgar en 1920, habría impulsado este plan ${ }^{67}$. Por sí solo, el tendido de una red eléctrica nacional no habría aportado en los decenios de 1920 y 1930 más de lo que las propias compañías habían procurado: tender líneas de transporte entre sus centros de producción y aquellos de consumo y vincular algunos de los grandes centros productivos con líneas de intercambio, pero sin ejercer ningún control centralizado de cargas. La puesta en uso de grandes establecimientos había contribuido a que a partir de 1926 las potencias de transporte en España fueran cada vez mayores -hasta $150.000 \mathrm{kV}$ en el caso de Saltos del Duero, en Castilla, en 1935- y a que, de hecho, se efectuase una interconexión de carácter espontáneo antes de la Guerra Civil. A través de la línea de Lafortunada y del cableado de Saltos del Duero, se habían conectado los cuatro grandes núcleos productores de la península: Cataluña-Aragón con País VascoCantabria; estos últimos con Saltos del Duero y ésta a través de Madrid con Levante, aunque Levante no se coordinase con Cataluña, aumentando los intercambios entre las diferentes zonas de 11,3 por cien en 1929 a 29,3 por cien en $1935^{68}$.

${ }^{64}$ Sin considerar ni el coste de las centrales complementarias ni el de la electrificación de líneas ferroviarias que su proyecto también contemplaba. Mayoral (1921). En Francia, el proyecto de auxilio público más ambicioso, que es el de 1938, preveía 10.000 millones de francos franceses para la construcción de grandes saltos y la construcción de la red. La línea Norte-Este absorbería por sí sola 350 de estos millones. Levy-Levoyer (1994, p. 112).

${ }^{65}$ El nitrato de calcio era casi la única producción intensiva viable desde el punto de vista del coste del kWh, pero sus competidores ejercían dumping comercial. Errandonea (1935a, p. 259).

${ }^{66}$ El entrecomillado del preámbulo a la Real Orden que el 28 de diciembre de 1918 (Gaceta del 31) que instaba a la CPEE a emitir un informe sobre la Red Nacional.

${ }^{67} \mathrm{Su}$ optimismo le llevaba a considerar que la red nacional sería rentable de modo inmediato y que arrastraría al resto de la demanda industrial El artículo emblemático, y referencia obligada de los posteriores, fue el que publicó Pérez del Pulgar (1920).

${ }^{68}$ Otros mercados regionales integrados eran el andaluz y el de la costa gallega, que más tarde acabarían conectado con Saltos de Duero y el sistema vasco-cantábrico respectivamente. Pedro Amigo (1992) coincide en advertir que estas líneas eran más de transporte que de coordinación de mercados, aunque este último objetivo tampoco se desdeñase completamente. Los datos sobre concentración y trasvases entre sistemas proceden de Lucía (1941, pp. 11-12). 
Los problemas institucionales sobrevendrían al cabo a los hasta aquí enunciados: los intereses contrarios -compañías de generación y sociedades carboneras- se hicieron visibles en las respuestas a la consulta de 1926, en el marco de una Administración voluntariosa, pero que carecía de capacidad de gestión y de financiación para afrontar la construcción de la red ${ }^{69}$. Las compañías eléctricas se mostraron siempre remisas a la intervención y las conexiones que interesaban las efectuaron por su cuenta ${ }^{70}$. Los carboneros, a su vez, querían evitar la puesta en peligro de sus intereses con la eventual electrificación de los ferrocarriles ${ }^{71}$. En fin, el tendido de una red nacional sólo habría sido viable en un clima de legitimación política, de «fiebre eléctrica», del que España no se contagió durante la Dictadura, y que la Segunda República procuró arrumbar ${ }^{72}$. Con todo, la integración del mercado eléctrico español se haría esperar incluso más allá de lo razonable ${ }^{73}$.

\section{CONCLUSIONES}

Hasta 1936, la integración física de los mercados eléctricos españoles no disfrutó de auxilios al tendido de líneas y, además, el ciclo de la transmisión quedó excluido de regulación por parte de las autoridades. Pese a que la Administración fijó consultas para el tendido de una red nacional, los proyectos no prosperaron. Aunque hasta ahora se ha creído que fueron factores institucionales los que más pesaron al postergar el tendido de una red eléctrica nacional, prevalecieron a mi juicio los criterios económicos que convertían esta propuesta en inviable. Si bien el rendimiento del sistema eléctrico era comparable al de países que se decidieron al tendido de la red, estos últimos empleaban mayoritariamente el carbón. Aquí la red no contribuiría a diversificar las fuentes de energía, como en Francia, pero involucraba un plan costoso de desarrollo vía exceso de capacidad de infraestructuras de generación y de industrias altamente consumidoras. Las compañías acometieron las conexiones que estimaron provechosas y el Estado se abstuvo, en

${ }^{69}$ Sintés y Vidal (1933, p. 460) insisten en la incapacidad del Estado como una razón básica de su inacción: «[...] creemos que la Red Nacional es una de tantas fantasías de la Dictadura que sólo podría realizarse a costa de un sacrificio enorme para el Estado, por grande que fuera la voluntad de construir y explotar la Red en forma económica por parte de la Entidad concesionaria».

${ }^{70}$ Este hecho lo apuntan tanto Pedro Amigo (1992), Núñez (1992) y Antolín (1999).

${ }^{71}$ Los proyectos de la entonces Asociación de Productores y de la Hullera Nacional fueron resumidos por Sintés y Vidal (1933, pp. 452 y ss). La oposición a la electrificación de los ferrocarriles en Bartolomé (2003, cap. 5).

${ }^{72}$ Véase por ejemplo el tratamiento marginal de los aprovechamientos hidroeléctricos en el Plan Nacional de Obras Hidráulicas de 1933 . Ministerio de Obras Publicas (1933, pp. 123147).

${ }^{73}$ La conexión Oeste/Norte no culminó hasta 1966. Esta corrió a cargo de la empresa INTOESA de capital público minoritario. Tora (1983). 
buena lógica, por cuanto a mercados en formación, le correspondían todavía conexiones a escala regional.

Lamentablemente, el círculo vicioso entre la escasez de la oferta y de la demanda eléctrica en España no mudaría de inmediato en círculo virtuoso mediante la construcción de la red nacional, como con cierta ingenuidad supusieron los ingenieros de la CPEE en $1918^{74}$. Su fracaso constituye, pues, una falsa pista del retraso del sector eléctrico español palpable desde 1925, por cuanto todo indicaría que al postergar su tendido triunfó el interés general sobre propuestas autárquicas poco sensatas.

Esta suposición de que la red nacional fuera la gran oportunidad perdida por el sector público español antes del la Guerra Civil deriva quizá de otra circunstancia: a lo largo de la segunda mitad del siglo XX el Estado intervino promoviendo industrias de consumo y grandes centrales pero se abstuvo de ordenar el caos en que se convertiría la transmisión de electricidad. Ejecutada en mercados regionales discontinuos, las economías del alto voltaje acabarían perdiéndose en España tanto por la ausencia de un organismo regulador como por la falta de una autopista eléctrica. Y en esa investigación, sí, las variables institucionales resultarían decisivas.

\section{FUENTES}

Archivo Estafeta-Instituto Nacional de Industria AE-INI (Madrid).

Anuario Financiero y Sociedades Anónimas de España (AFSAE)

\section{BIBLIOGRAFÍA}

Amigo Román, P. (1992): «La formación del mercado eléctrico nacional en España: la aportación de Castilla y León». Cuadernos de Economía de Castilla y León 2, pp. 119-53.

Antolín, F. (1999): «Iniciativa privada y política pública en el desarrollo de la industria eléctrica en España. La hegemonía de la gestión privada, 1875-1950». Revista de Historia Económica 17 (2), pp. 411-45.

Artiñano, G. (1921): «España puede y debe ser la primera nación que establezca la red nacional de distribución de energía eléctrica». La Energía Eléctrica, pp. 92-101.

\footnotetext{
${ }^{74}$ «Sin energía barata no pueden desarrollarse las grandes industrias y sin industrias consumidoras no se arriesgan los capitales a establecer centrales y redes de capacidad necesaria para producir energía a bajo precio. Solamente la intervención del Estado puede romper este círculo de hierro, tomando a su cargo el establecimiento de una red general que permita el establecimiento de grandes centrales productoras y grandes industrias consumidoras». Proyecto (1919, p. 83).
} 
BARTOLOMÉ, I. (1999): «La industria eléctrica española antes de la guerra civil: reconstrucción cuantitativa». Revista de Historia Industrial 15, pp. 139-60.

- (2003): «La industria eléctrica en España (1880-1936). Tecnología, recursos e instituciones». Florencia: Instituto Universitario Europeo. Tesis doctoral sin publicar.

CARmona, J. (1999): «Galicia en el desarrollo del sector eléctrico español (1900-1982)», en A. Carreras et al. (eds.), Dtor. Jordi Nadal. La industrialització y el desenvolupament economic d'Espany. Barcelona: UB, vol. 2, pp. 1378-97.

Carreras, A. (coord.) (1989): Estadísticas históricas de España, ss. XIX y XX. Madrid: Banco Exterior.

CASTEL, J. (1936): Legislación protectora de la producción nacional, recopilada, anotada y comentada por -. Madrid: Revista de los Tribunales.

Congreso Nacional de Ingeniería (1919): Actas. «Reconstitución Nacional», Sección 12a . Madrid: Soc. Esp. de Artes Gráficas, 3 volúmenes.

Copde (1935-6): Datos Estadístico técnicos de las centrales eléctricas españolas correspondientes. Madrid: Suc. de Rivadeneyra.

De la Fuente, F. (1908): «El fraude en los contadores eléctricos». Madrid Científico 587, p. 123.

Eden, R. J. et al. (1981): Energy Economics. Growth, Resources and Policy. Cambridge: Cambridge U. Press.

ERRANDONEA, E. (1935a): «Desarrollo y producción de la electricidad en España». Ibérica 27 de abril, p. 259.

- (1935b): «La economía de la producción eléctrica en España». Ingeniería y Construcción 153, septiembre, pp. 529-35.

Etemad, B. y Luciani, J. (1991): World Energy Production, 1860-1985. Ginebra: Droz.

García Rodrigo, M. (1927): Legislación eléctrica. Madrid: Revista de los Tribunales.

Germán, L. (ed.)(1990): ERZ. (1910-1990). El desarrollo del sector eléctrico en Aragón. Zaragoza: Institución Fernando el Católico.

GiannetTi, R. (1985): La conquista della forza: risorse, tecnologia ed economia nella industria elettrica italiana (1883-1940). Milán: Franco Angeli

— (1991): «I 'sisteme’ elettrici italiani. Struttura e prestazioni dalle origini al 1940», en B. Bezza (ed.), L'industria elettrica italiana e la societá Edison. Torino: Einaudi.

- (1995): «From Small Insulated Plants to Regional Networks: the Path of Growth of the Italian Electrical Industry from its Beginning to the 1930s», en F. Caron, P. Erker y W. S. Fisher (eds.), Innovations in the European Economy between the Wars. Berlín, Nueva York: W. de Gruyter.

- (1997): «Tecnologie di rete e intervento pubblico nel sistema elettrico italiano (18831996)». Storia Economica (agosto), pp. 127-60.

GILBERT, R. J. y KaHn, E. P. (ed.) (1996): International Comparisons of Electricity Regulation. Cambridge: Cambridge Univ. Press.

Herranz LoCÁn, A. (2004): La dotación de infraestructuras en España, (1844-1935). Madrid: Banco de España.

Hughes, T. P. (1983): Networks of Power: Electrification in Western society, 18801930. Baltimore, Md.: Johns Hopkins University Press.

INE (varios años): Anuario estadístico de España. Madrid: Dirección General de Estadística.

Joskow, P. (1996): «Introducing Competition into Regulated Network Industries: from Hierarchies to Markets in Electricity». Industrial and Corporate Change, pp. 341-80. 
Joskow, P. y Schmalensee (1983): Markets for Power. An Analysis of Electrical Utility Deregulation. Cambridge, Mass.: MIT.

Kauser, A. (1987): «From local Networks to National Systems», en F. Cardot (ed.), Un siècle d'électricité dans le Monde. París: PUF, pp. 7-22.

Lanthier, P. (1994): «L'électricité en France: Marchés, Réseau et Pouvoirs Publics, 18801940», en A. Beltran y H. Morsel (eds.), Electricity Generation and Supply: Regulation, Market, Competition. International Comparisons. Milán: Universita Bocconi.

Levy-Levoyer, M. (1994): «Panorama de l'électrification. De la grande guerre à la nationalisation», en M. Levy-Leboyer y $\mathrm{H}$. Morsel (eds.), L'Interconnexion et le Marché 1919-1946, Histoire Générale de l'électricité en France. París: PUF, t. 2, pp. 13 y ss.

Lucía, P. J. (1941): «La electricidad en España», en Electricidad. Sin Lugar: Publicaciones de la Asociación de Ingenieros de Caminos, Canales y Puertos, pp. 3-26.

Madureira, N. L. (2004): «Asymmetry of Adoption and the Electric Network. Portugal 1920-1947». Comunicación presentada a Business History Conference, Annual Meeting Program. Le Creusot.

Maluquer de Motes, J. (1986): «L'electricitat». Ejemplar mecanografiado, sin publicar.

MAYoRAL, D.(1921): «La interconexión y la electrificación general de España ». La Electricidad, p. 25.

MilwaRd, R. (2004): «Economic and Institutional Factors in Electricity Network Integration in Western Europe c. 1900-50». EBHA Conference. Barcelona.

Ministerio de Obras Públicas. Centro de Estudios Hidrográficos (1933): Plan Nacional de Obras Hidráulicas. Madrid: Sucesores de Rivadeneyra Artes Gráf., Tomo II. Datos fundamentales. Anejo VIII, pp. 123-47.

Montañés, C. (1924): «Primera reunión en Londres de la Conferencia Internacional de la Energía». Ingeniería y Construcción, pp. 450-52.

- (1935): La Red Eléctrica Nacional. Estudio del problema eléctrico español en orden a su aspecto nacional y conveniente actuación del Estado. Madrid: Dirección General de Industria, Publicaciones del Consejo de Industria.

Morsel, H. (1987): «Panorama de l'histoire de l'électricité dans la première moitié du XXe siècle», en F.Cardot (ed.), Un Siècle d'électricité dans le monde, 1880-1980. París: PUF, pp. 85-117.

- (1991): «L’hydroéletricité», en F. Caron y F. Cardot (eds.), Histoire Générale de l'electricité en France, Spoirs et conquêtes 1881-1918. París: PUF, t. 1, pp. 594 y ss.

Mortara, G. (1934): Lo sviluppo dell'industria elettrica nel mondo. Milano: Società Edison. Istituto Grafico Raffaello Bertieri, Volumen I.

Myluintaus, T. (1991): Electrifying Finland. The Transfer of a New Technology into a Late Industrialising Economy. Londres: Macmillan.

Nadal, J. (1970): «La economía española, 1829-1936», en F. Ruiz Martín et al., El Banco de España. Una historia Económica. Madrid : Banco de España.

NuÑEz-Romero-Balmas, G. (1992): «Développement et intégration régionale de l'industrie électrique en Andalousie jusqu'en 1935», en M. Trédé, Électricité et électrification dans le monde (1880-1980). París: PUF, p. 169-201.

— (1995): «Empresas de producción y distribución de electricidad en España (1878-1953)». Revista de Historia Industrial 7, pp. 199-227. 
OtтоLino, M. (1993): «L'evoluzione legislativa», en L. de Rosa (ed.), Il potenziamento tecnico e finanziario 1914-1925, Storia dell'industria elettrica in Italia. Roma: Laterza, t. 2., vol. 2, pp. 465-509.

Peirce, W. S. (1996): Economics of the Energy Industries. Westport, London: Praeger.

Pérez de Pulgar (1915): «La energía eléctrica en la vida industrial moderna». Ibérica 104 diciembre, p. 411.

- (1917): «Suelto». Ibérica (octubre).

- (1920): «Suelto». Ibérica ( 24 de mayo).

Proyecto (1919): «Proyecto de una Red General de Distribución de Energía Eléctrica en España». La Energía Eléctrica, pp. 82-109.

RamunNI, G. (1987): «L'élaboration du résau éléctrique française. Un débat technique de l'entre-deux-guerres», en F. Cardot (ed.), Un siècle d'électricité dans le monde (18801980). París: PUF.

SÁnchez Cuervo, L. (1935): «La red nacional de transporte de energía». Ingeniería y Construcción diciembre, pp. 705-7.

SegReto, L. (1993): «Aspetti e problemi dell'industria elettrica in Europa tra le due guerre», en G. Galazo, Storia dell'industria elettrica in Italia. Espansione e Oligopolio. 19261945. Roma: Laterza, pp. 325-398.

Sindicato Nacional de Agua, Gas y Electricidad. Delegación Sindical de Estadísticas (1960): Datos estadístico-técnicos de las centrales eléctricas españolas en 1958. Madrid: Pueblo imp.

Sintés OlivÉs, F. F. y Vidal Burdil, F. (1933): La industria eléctrica en España. Barcelona: Montaner y Simón.

Sirvent I., Mouton, E. y De la Fuente, M. (1960): «Consideraciones sobre el desarrollo de la red de transporte de energía eléctrica en España», Conferencia Mundial de la Energía, Actas. Madrid: Suc. de Ribadeneyra, Vol. VI, pp. 3379-94.

SudRIÀ, C. (1990): «La industria eléctrica y el desarrollo económico en España», en J. L. García Delgado (ed.), Electricidad y desarrollo económico: perspectiva histórica de un siglo. Oviedo: Hidroeléctrica del Cantábrico, pp. 155 y ss.

- (1997): «La restricción energética al desarrollo económico de España». Papeles de Economía Española 73, pp. 165-88.

Thue, L. (1992): «The State and the Dual Structure of the Power Supply Industry in Norway, 1840-1940», en M. Trédé (ed.), Electricité et électrification dans le Monde. París: PUF.

Tora, J. L. (1983): «La Red Eléctrica Nacional». Papeles de Economía Española 14, pp. 210 y ss.

Turvey, R. (1971): «Rates of Return, Pricing and Public Interest». Economic Journal 81, pp. 489-501.

URrutia, J. (1918): La energía hidroeléctrica de España. Antecedentes que deben tenerse en cuenta al redactar la nueva ley de aprovechamientos hidráulicos para la producción de energía. Madrid.

VidAl BuRdils, F. F. (1941): Economía eléctrica de España. Barcelona: Montaner y Simón..

Williams, T. I. (1986): Historia de la Técnica. Desde 1900-1950. Madrid: Siglo veintiuno, v. III, t. I. 
ISABEL BARTOLOMÉ

APÉNDICE:

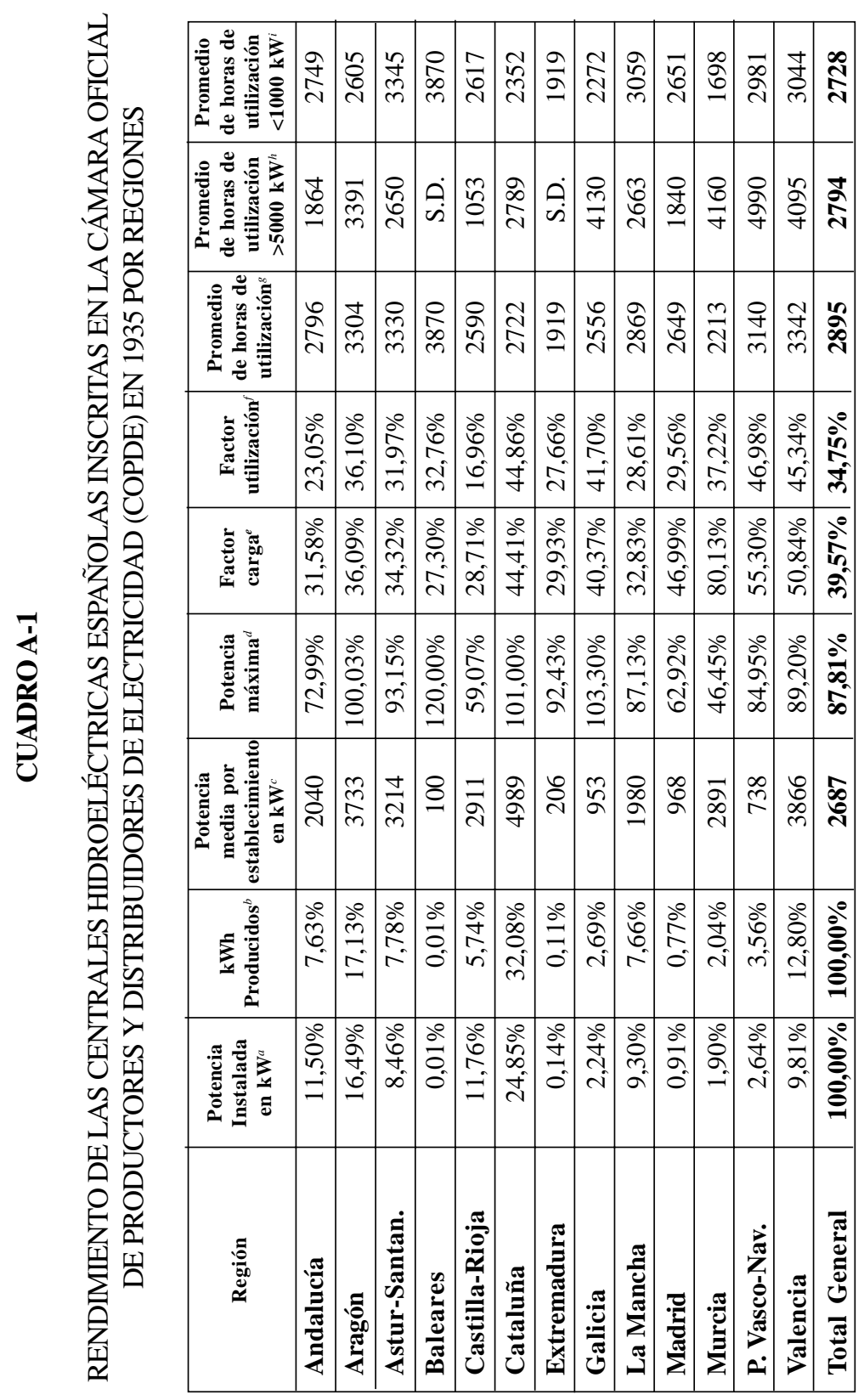


Fuente: COPDE (1936). Una lectura crítica de la fuente y el uso concreto que aquí se hace de las divisiones regionales en Bartolomé (1999).

Notas:

${ }^{a}$ Esta columna resume el porcentaje de potencia hidroeléctrica instalada por regiones en 1935.

${ }^{b}$ Porcentaje de los kWh producidos en 1935 por regiones.

${ }^{c}$ Promedio de potencia instalada por establecimiento inscrito en aquella estadística por regiones.

${ }^{d}$ Utilización de la potencia máxima en porcentaje.

${ }^{e}$ Factor Carga: ratio entre la producción efectiva durante un año con la potencial, si la potencia máxima alcanzada se hubiera mantenido durante todo el año. O lo que es lo mismo: producción efectiva durante un año en kWh *100 / 8.760 horas * Potencia instantánea máxima.

${ }^{f}$ Factor Utilización: relaciona la capacidad nominal de las máquinas eléctricas con la producción efectiva. Es decir: Producción efectiva durante un año *100/ 8.760 horas *100 *Potencia instalada en $\mathrm{kW}$.

${ }^{g}$ Medida con el mismo propósito que la anterior, pero que recoge el promedio de horas de utilización de la potencia instalada por regiones.

${ }^{h}$ Medida de horas de utilización en centrales grandes: mayores o iguales de $5.000 \mathrm{~kW}$ instalados.

${ }^{i}$ Medida idéntica a la anterior columna en centrales pequeñas: menores o iguales de $1.000 \mathrm{~kW}$ instalados. 
